\title{
Соблюдение баланса интересов как ключевой фактор роста рыночной стоимости предприятия
}

\author{
Тонких А.С. ${ }^{19}$, Ионов А.В. ${ }^{20}$
}

В настоящей статье обосновывается мысль, что баланс интересов акционеров $и$ менеджеров предприятия является главным условием роста рыночной стоимости предприятия. Проведена оценка влияния баланса интересов на стоимость акиий крупнейших российских предприятий. Выдвинута гипотеза о зависимости роста рыночной стоимости фирмы в посткризисный период от количественного значения баланса интересов.

JEL: G11, G12, G14, G32, G34, O16, C15

Ключевые слова: стоимость бизнеса, рыночная стоимость, управление стоимостью, баланс интересов, корпоративное управление

По нашему мнению, основным драйвером роста рыночной стоимости бизнеса выступает соблюдение баланса финансовых интересов акционеров и менеджеров предприятия [Тонких, Ионов, 2009].

Рыночная стоимость предприятия формируется в зависимости от его внутренней стоимости. Внутренняя стоимость бизнеса у каждого инвестора разная и зависит от его личных предпочтений. При этом инвесторы придают разную значимость различным аспектам деятельности предприятия. Для того чтобы произошло значительное изменение стоимости бизнеса, большинство инвесторов должны осознать, что фирма создает ценности для своих акционеров и их совместное сотрудничество экономически целесообразно. Чем большее количество потенциальных и настоящих инвесторов удовлетворены результатами деятельности фирмы, тем выше ее рыночная стоимость. Учитывая разнородность требований инвесторов, обеспечить их одинаково позитивное восприятие фирмы достаточно сложно. Неясность критериев оценки деятельности предприятия со стороны рынка усиливает неопределенность в принятии решений по управлению стоимостью предприятия. Нужен инструментарий, позволяющий согласовывать разнородные требования инвесторов и разрабатывать мероприятия по улучшению баланса интересов, приводящие к росту рыночной стоимости.

Управление рыночной стоимостью предприятия нацелено на ее рост, а не на максимизацию. Увеличение рыночной стоимости является следствием роста внутренней стоимости в глазах большинства инвесторов. Чем большее количество потенциальных владельцев бизнеса осознают его способность создавать ценности для своих собственников, тем выше как рыночная стоимость бизнеса, так и стоимость его акций. Оценивая данную способность, субъекты рынка делают это либо самостоятельно, либо прибегают к помощи третьих лиц - аналитиков. Независимо от того, кто производит оценку, в ее основе лежит анализ показателей деятельности. Бывают, конечно, ситуации, когда инвестор принимает интуитивные решения, но это, как правило, исключение. Поэтому управление стоимостью бизнеса осуществляется посредством управления ключевыми показателями деятельности.

Проблема состоит в том, что инвесторы в качестве ключевых видят различные показатели. Так, для некоторых ценность заключается в росте объемов реализации, которая, по их мнению, характеризует конкурентоспособность продукции и возможность генерировать значительные денежные потоки. Для других важен размер фирмы,

\footnotetext{
19 Д-р эконом. наук, Глазовский инженерно-экономический институт, профессор.

${ }^{20}$ Глазовский инженерно-экономический институт, соискатель.
} 
выраженный показателем совокупных активов. Они полагают, что чем больше имущества у фирмы, тем она дороже. Третьи обращают внимание на размер прибыли, которая, по их мнению, является показателем эффективности деятельности и источником их текущих доходов в виде дивидендов и т.д. Поэтому в целях управления стоимостью фирмы необходимо согласовывать разнородные требования собственников, находить баланс интересов, что является залогом высокой оценки внутренней и, как следствие, рыночной стоимости. Для взаимного согласования разнородных интересов, выраженных различными показателями, воспользуемся построением так называемой эталонной динамики показателей, или методом динамического норматива [Сыроежин, 1980].

В работе одного из авторов статьи [Тонких, 2006] представлено доказательство следующего упорядочения темпов ключевых показателей:

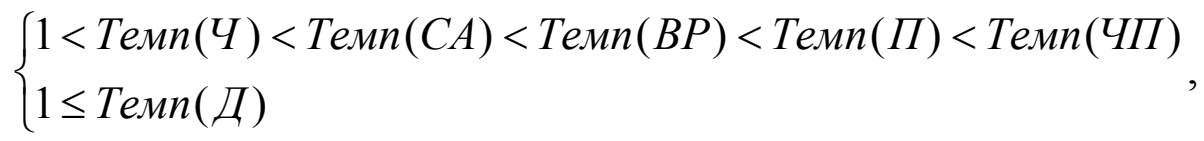

где

Tемn $(a)$
4
$C A$
ВР
$\Pi$
ЧП
Д

$$
\begin{array}{ll}
- & \text { темп роста показателя } a ; \\
- & \text { численность работающих; } \\
- & \text { сумма совокупных активов; } \\
- & \text { выручка от реализации продукци } ; \\
- & \text { прибыль до налогообложения; } \\
- & \text { прибыль после выплаты процентов } \\
- & \text { сумма выплаченных дивидендов. }
\end{array}
$$$$
\text { - численность работающих; }
$$$$
\text { - выручка от реализации продукции; }
$$$$
\text { - прибыль после выплаты процентов и налогов; }
$$

Темп роста показателя рассчитывается по формуле (2).

$$
\begin{array}{ccl}
\text { где } \quad \text { Темп }(a) & - & \text { темп роста показателя } a ; \\
a_{2} & - & \text { значение показателя } a \text { в текущем периоде; } \\
a_{1} & - & \text { значение показателя } a \text { в предыдущем периоде. }
\end{array}
$$

$$
\operatorname{TeMn}(a)=\frac{a_{2}}{a_{1}}
$$

Доказательство представленного порядка основано на простых логических рассуждениях. Например, рост выручки должен быть большим по сравнению с ростом совокупных активов, что свидетельствует об улучшении деловой активности предприятия, выраженной оборачиваемости активов. Или более быстрый рост прибыли по отношению к выручке указывает на то, что доходы предприятия увеличиваются более быстрыми темпами, чем расходы, что демонстрирует рынку эффективность работы предприятия. Данное соотношение известно еще как «золотое правило экономики предприятия» [Кашин, 2004].

Следование данной динамике показателей характеризует высокую степень сбалансированности интересов и способность создавать ценность для своих владельцев, увеличивает в глазах инвесторов внутреннюю стоимость, что в итоге выливается в рост рыночной стоимости бизнеса. Представление баланса интересов в виде (1) позволяет количественно оценить степень его соблюдения. Делается это на основе расчета нормированного расстояния между матрицами, соответствующими эталонному и фактическому порядку темпов. Для облегчения расчетов нами разработана специальная компьютерная программа, которую мы разместили в свободном доступе в сети Интернет по адресу www.freean.ru, чтобы любой желающий мог произвести необходимые расчеты.

Количественное значение баланса интересов имеет привычную размерность и изменяется от 0 до $100 \%$. Это позволяет достаточно легко интерпретировать полученные результаты. Так, 100\% означает, что достигнут максимально возможный баланс интересов, $0 \%$ - баланс интересов полностью отсутствует. В зависимости от полученного числового 
значения предприятия можно отнести к тому или иному классу сбалансированности интересов. С этой целью мы предлагаем соответствующую классификацию (табл.1).

Таблица 1

Классификация предприятий по сбалансированности интересов

\begin{tabular}{|c|c|}
\hline От 0 до 20\% & $\begin{array}{l}\text { Отсутствует уровень сбалансированности интересов, менеджеры не } \\
\text { стремятся соблюдать интересы акционеров и не ориентированы на рост } \\
\text { рыночной стоимости }\end{array}$ \\
\hline От 20 до $30 \%$ & $\begin{array}{l}\text { Низкий уровень сбалансированности корпоративных интересов, однако } \\
\text { имеются ограничения в деятельности менеджеров, вынуждающие их по } \\
\text { некоторым показателям показывать достойные результаты, рост } \\
\text { рыночной стоимости бизнеса не является их главной целью }\end{array}$ \\
\hline От 30 до 40\% & $\begin{array}{l}\text { Уровень сбалансированности интересов ниже среднего, для } \\
\text { обеспечения высокого социального статуса менеджеры добиваются } \\
\text { высоких результатов отдельных показателей, отвечающих их } \\
\text { специфическим интересам, что в некоторых случаях благоприятно } \\
\text { отражается на стоимости бизнеса }\end{array}$ \\
\hline От 40 до 50\% & $\begin{array}{l}\text { Средний уровень сбалансированности интересов, со стороны } \\
\text { владельцев организован частичный внутрикорпоративный контроль, } \\
\text { что способствует соблюдению интересов не только менеджеров, но и } \\
\text { некоторых ключевых собственников, для которых рост стоимости } \\
\text { бизнеса является желательной, но не основной целью }\end{array}$ \\
\hline От 50 д & 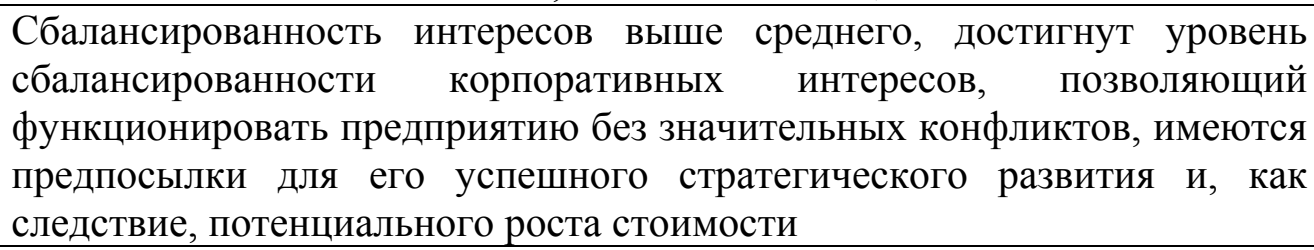 \\
\hline От 60 до 70\% & $\begin{array}{l}\text { Высокий уровень сбалансированности интересов, деятельность } \\
\text { менеджеров является для потенциальных инвесторов сигналом о } \\
\text { стремлении соблюдать их финансовые интересы независимо от суммы } \\
\text { их вклада в деятельность предприятия, что, по их мнению, увеличивает } \\
\text { внутреннюю стоимость предприятия }\end{array}$ \\
\hline От 7 & $\begin{array}{l}\text { Очень высокий уровень сбалансированности интересов, интересы } \\
\text { менеджеров совпадают с интересами большинства участников } \\
\text { корпоративных отношений, однако в отдельных направлениях } \\
\text { деятельности интересы менеджеров превалируют, что отчасти } \\
\text { сдерживает рост рыночной стоимости }\end{array}$ \\
\hline От 80 до 90\% & $\begin{array}{l}\text { Очень высокий уровень сбалансированности интересов, моральная и } \\
\text { материальная удовлетворенность менеджеров напрямую зависит от } \\
\text { достижения баланса интересов, сильные акционеры не только } \\
\text { организовали эффективный внутрикорпоративный контроль, но и } \\
\text { смогли нанять отвечающий их интересам менеджмент, влечет за собой } \\
\text { существенный прирост стоимости бизнеса }\end{array}$ \\
\hline От 90 до 100\% & $\begin{array}{l}\text { Высшая степень сбалансированности корпоративных интересов, все } \\
\text { участники корпоративных отношений удовлетворены достигнутыми } \\
\text { результатами, менеджеры - профессионалы высочайшего уровня, } \\
\text { сумевшие увязать свои интересы с интересами других субъектов; } \\
\text { развитию предприятия в ближайшем будущем ничего не угрожает в } \\
\text { силу высокой способности соответствовать ожиданиям интересов, } \\
\text { максимально возможный рост рыночной стоимости }\end{array}$ \\
\hline
\end{tabular}


Подобная градация вытекает из логики построенного измерителя, является естественным продолжением самого критерия, хотя может допускать определенные уточнения исходя из потребностей, склонностей и предпочтений конкретного инвестора.

Для подтверждения нашей гипотезы о зависимости рыночной стоимости от достигнутого баланса интересов проведем ее эмпирическую проверку. Для этого проанализируем баланс интересов ряда крупнейших российских предприятий. Чтобы объективно оценить рыночную стоимость, возьмем предприятия, акции которых активно обращаются на бирже. Хотя это не является обязательным условием, тем не менее гарантирует объективность информации и «очищает» рыночную стоимость от неформализованных (спекулятивных) факторов (табл. 2).

Таблица 2

Количественное значение баланса интересов и прироста рыночной стоимости крупнейших российских предприятий за период 2002-2007 годов

\begin{tabular}{|c|c|c|c|c|c|c|c|c|c|}
\hline $\begin{array}{l}\text { № } \\
\text { пI/I }\end{array}$ & ПРЕДПРИЯТИЯ & $\begin{array}{c}\text { Показа } \\
\text { тель }\end{array}$ & 2002 & 2003 & 2004 & 2005 & 2006 & 2007 & КК \\
\hline \multirow{2}{*}{1} & \multirow[t]{2}{*}{ Автоваз } & БИ,\% & 43,75 & 68,75 & 87,5 & 37,5 & 87,5 & 81,25 & \multirow[t]{2}{*}{0,344} \\
\hline & & ПК, \% & & 15,6 & 0,4 & 33,5 & 71,8 & 163,1 & \\
\hline \multirow[t]{2}{*}{2} & \multirow[t]{2}{*}{ КамАЗ } & БИ,\% & 70,59 & 31,25 & 81,25 & 87,5 & 87,5 & 87,5 & \multirow[t]{2}{*}{0,691} \\
\hline & & ПК,\% & & 1,5 & 26,2 & 95,6 & 107,9 & 143,3 & \\
\hline \multirow[t]{2}{*}{3} & \multirow[t]{2}{*}{ Уралкалий } & БИ,\% & 81,25 & 71,25 & 93,75 & 93,75 & 93,75 & 75 & \multirow[t]{2}{*}{$-0,125$} \\
\hline & & ПК,\% & & $-50,3$ & 351,2 & 239,9 & 25,2 & 339,2 & \\
\hline \multirow[t]{2}{*}{4} & \multirow[t]{2}{*}{ Метафракс } & БИ,\% & 43,75 & 87,5 & 31,25 & 93,75 & 93,75 & 75 & \multirow[t]{2}{*}{0,268} \\
\hline & & ПК,\% & & 42,0 & 36,4 & 4,3 & 21,3 & 25,2 & \\
\hline \multirow[t]{2}{*}{5} & \multirow[t]{2}{*}{ Акрон } & БИ,\% & 37,5 & 31,25 & 93,75 & 93,75 & 81,25 & 87,5 & \multirow[t]{2}{*}{0,526} \\
\hline & & ПК,\% & & 4,5 & 29,1 & 33,9 & 511,9 & 59,1 & \\
\hline \multirow[t]{2}{*}{6} & \multirow[t]{2}{*}{ Аэрофлот } & БИ,\% & 93,75 & 93,75 & 93,75 & 50 & 93,75 & 12,5 & \multirow[t]{2}{*}{0,192} \\
\hline & & ПК,\% & & 100,0 & 78,6 & 14,5 & 52,4 & 72,1 & \\
\hline \multirow[t]{2}{*}{7} & \multirow[t]{2}{*}{ Балтика } & БИ,\% & 62,5 & 56,25 & 50 & 93,75 & 43,75 & 37,5 & \multirow[t]{2}{*}{0,368} \\
\hline & & ПК,\% & & $-2,1$ & 17,0 & 87,9 & 73,6 & 8,1 & \\
\hline \multirow[t]{2}{*}{8} & \multirow[t]{2}{*}{ Вимм-Билль-Данн } & БИ,\% & 50 & 31,25 & 62,5 & 25 & 88,89 & 75 & \multirow[t]{2}{*}{$-0,356$} \\
\hline & & ПК,\% & & $-5,3$ & $-15,8$ & 67,9 & 176,9 & 20,0 & \\
\hline \multirow[t]{2}{*}{9} & Газпром & БИ,\% & 93,75 & 75 & 81,25 & 62,5 & 93,75 & 56,25 & $-0,265$ \\
\hline & & ПК,\% & & 59,5 & 96,1 & 150,6 & 55,4 & 14,0 & \\
\hline 10 & Татнефть & БИ,\% & 43,75 & 87,5 & 87,5 & 87,5 & 50 & 81,25 & 0,313 \\
\hline & & ПК,\% & & 42,9 & 13,6 & 162,9 & 39,4 & 31,0 & \\
\hline 11 & Лукойл & БИ,\% & 87,5 & 50 & 93,75 & 50 & 43,75 & 62,5 & 0,823 \\
\hline & & ПК,\% & & 38,9 & 21,7 & 106,8 & 33,7 & $-8,0$ & \\
\hline 12 & ГМК Норильский & БИ,\% & 12,5 & 93,75 & 87,5 & 81,25 & 93,75 & 68,75 & $-0,930$ \\
\hline & никель & ПК,\% & & 209,5 & $-17,2$ & 60,7 & 39,5 & 61,9 & \\
\hline 13 & Сургутнефтегаз & БИ,\% & 37,5 & 43,75 & 93,75 & 87,5 & 31,25 & 25 & 0,248 \\
\hline & & ПК,\% & & 57,8 & 36,3 & 29,4 & 33,2 & $-24,9$ & \\
\hline 14 & MTC & БИ,\% & 56,25 & 37,5 & 62,5 & 31,25 & 100 & 81,25 & 0,338 \\
\hline & & ПК,\% & & 113,9 & 68,1 & 6,2 & 39,9 & 96,5 & \\
\hline 15 & Ростелеком & БИ,\% & 87,5 & 93,75 & 50 & 87,5 & 31,25 & 87,5 & 0,241 \\
\hline & & ПК,\% & & 59,5 & $-13,9$ & 28,3 & 184,8 & 35,2 & \\
\hline 16 & Газпромнефть & БИ,\% & 81,25 & 68,75 & 93,75 & 31,25 & 87,5 & 68,75 & 0,328 \\
\hline & & ПК,\% & & 50,1 & 5,3 & 23,4 & 23,0 & 39,5 & \\
\hline 17 & MMK & БИ,\% & 37,5 & 87,5 & 87,5 & 37,5 & 93,75 & 68,75 & 0,807 \\
\hline & & ПК,\% & & 11,1 & 63,8 & 66,2 & 1,7 & 178,2 & \\
\hline 18 & НЛМК & БИ,\% & 93,75 & 75 & 93,75 & 18,75 & 81,25 & 37,5 & 0,143 \\
\hline & & ПК,\% & & $\mathrm{H} / \mathrm{A}$ & 10,6 & 66,6 & 47,8 & 57,7 & \\
\hline 19 & Уралсвязьинформ & БИ,\% & 81,25 & 87,5 & 56,25 & 62,5 & 50 & 93,75 & 0,408 \\
\hline
\end{tabular}




\begin{tabular}{|l|l|l|l|c|c|c|c|c|c|}
\hline & & ПК,\% & & 153,7 & $-4,1$ & 9,6 & 58,6 & $-9,7$ & \\
\hline \multirow{2}{*}{20} & ГАЗ & БИ,\% & 93,75 & 43,75 & 81,25 & 75 & 75 & 87,5 & 0,403 \\
\cline { 2 - 8 } & ПК,\% & 69,5 & $-13,7$ & 420,5 & 51,4 & 70,4 & \\
\hline
\end{tabular}

В соответствии с принципом общности в таблице 1 представлены предприятия различных отраслей: нефтяной, химической, автомобильной, металлургической, телекоммуникационной, пищевой, транспортной. Для каждого предприятия рассчитано значение баланса интересов по годам (БИ). С этой целью использовалась компьютерная программа, размещенная в свободном доступе на сайте «Новые технологии финансового анализа и корпоративного управления». БИ сопоставляется с приростом рыночной стоимости (капитализации) (ПК), рассчитанным по данным обязательной ежеквартальной отчетности эмитентов, находящихся в открытом доступе на официальных сайтах рассматриваемых предприятий.

С учетом того что баланс интересов можно оценить только после выхода официальной финансовой отчетности, можно ожидать, что реакция инвесторов на его состояние последует в следующем отчетном периоде. Поэтому зависимость между стоимостью бизнеса и балансом интересов, если она существует, должна оцениваться на основе сопоставления баланса интересов предыдущего отчетного периода с приростом капитализации в следующем отчетном периоде.

Оценим предполагаемую взаимосвязь на основе коэффициента корреляции Пирсона (столбец «КК» таблицы 1), рассчитанного с помощью встроенной функции пакета MS-Excel. По большинству предприятий прослеживается явная взаимосвязь между установленным балансом интересов и рыночной стоимостью бизнеса. Коэффициент корреляции положителен и достаточно далеко отстоит от нуля. Напомним, что коэффициент корреляции Пирсона изменяется от -1 до 1. 1 - означает полную корреляцию; -1 - обратную; 0 отсутствие корреляции. Только по четырем предприятиям из двадцати наблюдается отрицательная корреляция: «Газпром», «ГМК Норильский никель», «Вимм-Билль-Данн», «Уралкалий». Это может объясняться тем, что в отдельные моменты времени при формировании цены акций нефундаментальные факторы преобладали над фундаментальными. Например, борьба за контроль над «Норильским никелем» между основными акционерами, в рамках которой осуществлялась скупка акций, находящихся в свободном обращении, иногда, невзирая на цены, естественно вызвала рост их котировок, на наш взгляд, неоправданный. Или другой пример: одно время существовали ограничения на владение акциями «Газпрома» для нерезидентов, что, в свою очередь, ограничивало ликвидность и вносило искажения в справедливую рыночную цену акций.

Тем не менее средний коэффициент корреляции Пирсона, равный 0,238 , доказывает влияние соблюдения эталонной динамики (1) на рыночную стоимость бизнеса. Мы не ошибемся, предположив, что аналогичным образом данный факт отражается и в рыночной стоимости предприятий, акции которых не обращаются на бирже.

Чтобы оценить связь баланса интересов и рыночной стоимости, очищенную от влияния нефундаментальных, спекулятивных, краткосрочных факторов, а также показать долгосрочный характер этой связи, рассчитаем среднее значение баланса интересов по тем же компаниям за период 2002-2007 годов и сопоставим их с приростом рыночной стоимости за тот же период (табл. 3). 
Средние значения баланса интересов и прирост рыночной стоимости крупнейших российских компаний за период 2002-2007 годов

\begin{tabular}{|c|l|c|c|}
\hline № п/п & \multicolumn{1}{|c|}{ ПРЕДПРИЯТИЯ } & $\begin{array}{c}\text { Среднее } \\
\text { значение } \\
\text { баланса } \\
\text { интересов, \% }\end{array}$ & $\begin{array}{c}\text { Прирост } \\
\text { рыночной } \\
\text { стоимости 3a } \\
\text { период }\end{array}$ \\
\hline 1 & Автоваз & 67,71 & 6,00 \\
\hline 2 & КамА3 & $\mathbf{7 4 , 2 7}$ & $\mathbf{1 1 , 6 8}$ \\
\hline 3 & Уралкалий & $\mathbf{8 4 , 7 9}$ & $\mathbf{4 0 , 9 2}$ \\
\hline 4 & Метафракс & 70,83 & 2,06 \\
\hline 5 & Акрон & 70,83 & $\mathbf{1 6 , 6 0}$ \\
\hline 6 & Аэрофлот & 72,92 & 9,72 \\
\hline 7 & Балтика & 57,29 & 3,04 \\
\hline 8 & Вимм-Билль-Данн & 55,44 & 3,45 \\
\hline 9 & Газпром & 77,08 & $\mathbf{1 2 , 8 9}$ \\
\hline 10 & Татнефть & 64,58 & 6,79 \\
\hline 11 & Лукойл & 72,92 & 3,30 \\
\hline 12 & ГМК НорНик & 53,13 & 8,30 \\
\hline 13 & Сургутнефтегаз & 61,46 & 1,79 \\
\hline 14 & МТС & 72,92 & 9,50 \\
\hline 15 & Ростелеком & 71,88 & 5,78 \\
\hline 16 & Газпромнефть & 68,75 & 2,35 \\
\hline 17 & ММК & 66,67 & 7,56 \\
\hline 18 & НЛМК & 71,88 & 3,29 \\
\hline 19 & Уралсвязьинформ & $\mathbf{7 6 , 0 4}$ & 2,82 \\
\hline 20 & ГАЗ & $\mathbf{1 8 , 6 4}$ \\
\hline & Коэффициент корреляции Пирсона & $\mathbf{0 , 6 5 3}$ \\
\hline & & & \\
\hline
\end{tabular}

Серым фоном выделены ячейки, соответствующие максимальным значениям показателей в столбцах таблицы. Можно заметить интересную картину: максимальным значениям баланса интересов соответствуют максимальные значения прироста. Здесь «Газпром» выглядит одним из лучших. Его стоимость за анализируемый период выросла в 13 раз при среднем значении баланса интересов 77,08\%. Это говорит о том, что, поддерживая на высоком уровне баланс интересов в течение длительного периода времени, предприятию гарантировано повышенное внимание со стороны инвесторов и обеспечен значительный рост стоимости бизнеса в долгосрочной перспективе. Хотя, как в случае с «Газпромом», в отдельные периоды времени может наблюдаться определенное несоответствие баланса интересов и роста стоимости.

Точно так же выглядит и «Уралкалий», у которого связь баланса интересов и рыночной стоимости вроде бы не наблюдается, коэффициент корреляции Пирсона равен 0,125. Однако поддержание баланса интересов на высоком уровне в течение длительного периода времени (максимальное значение из представленных) позволило продемонстрировать соответствующий максимальный рост стоимости акций. При этом зависимость (корреляция) на длительном временном интервале гораздо выше, чем на коротких промежутках времени. То есть рынок, пусть и во многом на интуитивном уровне, высоко ценит успехи менеджмента предприятий в стремлении к балансу интересов.

Ни краткосрочные спекуляции, ни экономические кризисы при адекватном соблюдении баланса интересов не подорвут веру инвесторов в светлое будущее фирмы. Даже при ухудшении экономической конъюнктуры, в условиях которой снижение 
стоимости акций неизбежно, это объективная ситуация: восстанавливать свою стоимость будут прежде всего предприятия с высоким уровнем баланса интересов. В подтверждение этому посмотрим, как выглядели наши лидеры по уровню баланса интересов в период восстановления фондового рынка: октябрь 2008 года (пик кризиса на фондовом рынке) начало июня 2009 года (локальные максимумы на рынке акций) (табл. 4).

Таблица 4

Рост стоимости акций крупнейших российских предприятий в октябре 2008 года - начале июня 2009 года

\begin{tabular}{|c|c|c|c|c|}
\hline Предприятие & $\begin{array}{c}\text { Баланс } \\
\text { интересо } \\
\text { в, \% }\end{array}$ & $\begin{array}{c}\text { Максималь } \\
\text { ная цена за } \\
\text { период, } \\
\text { руб./акцию }\end{array}$ & $\begin{array}{c}\text { Минимальн } \\
\text { ая цена за } \\
\text { период, } \\
\text { руб./акцию }\end{array}$ & $\begin{array}{c}\text { Рост } \\
\text { стоимости, } \\
\text { раз }\end{array}$ \\
\hline Уралкалий & 84,79 & 129,50 & 21,50 & 6,02 \\
\hline Газпром & 77,08 & 191,57 & 84,00 & 2,28 \\
\hline КамА3 & 74,27 & 43,33 & 12,03 & 3,60 \\
\hline Татнефть & 72,92 & 153,55 & 26,21 & 5,86 \\
\hline Аэрофлот & 72,92 & 42,00 & 19,56 & 2,15 \\
\hline ГМК Норильский никель & 72,92 & 3756,00 & 1180,11 & 3,18 \\
\hline Ростелеком & 72,92 & 350,05 & 170,62 & 2,05 \\
\hline $\begin{array}{l}\text { Индекс ММВБ (рынок в } \\
\text { целом) }\end{array}$ & & 1226,61 & 509,00 & 2,41 \\
\hline Индекс РТС (рынок в целом) & & 1202,64 & 492,59 & 2,44 \\
\hline
\end{tabular}

«Уралкалий», обладая наивысшей из представленных предприятий степенью сбалансированности интересов, является одновременно и лидером по восстановлению рыночной стоимости. Цена его акций за рассматриваемый период увеличилась в 6 раз. Другие наши лидеры по сбалансированности интересов также интенсивно восстанавливали свои позиции. Стоимость акций «КамАЗа» (3-е место по сбалансированности) выросла в 3,6 раз, «Татнефть» (4-е место) в 5,9 раз, «ГМК Норильский никель» (4-е место) в 3,18 раз. Особенно примечательным является то, что рост рыночной стоимости упомянутых эмитентов существенно превышал рост рынка в целом (см. строки «Индекс ММВБ» и «Индекс РТС»). В среднем рынок вырос «лишь» в 2,4 раз. Тем не менее ряд лидеров по сбалансированности интересов не показали впечатляющих результатов. «Газпром» вырос «всего» в 2,28 раз, «Аэрофлот» - в 2,15 раз, «Ростелеком»- в 2,15 раз. В их оправдание можно заметить, что рост цены их акций в целом соответствовал росту всего рынка (индексы выросли в 2,4 раза), то есть они выглядели не хуже рынка. Более того, раз сами биржевые индексы показали скромные результаты восстановления, при наличии экстрароста и роста в рамках рынка наиболее ликвидных ценных бумаг, а также учитывая методику расчета индекса РТC [Сайт РТC], можно утверждать, что подавляющее большинство акций, обращающихся на фондовом рынке, показали рост гораздо меньший, чем наши лидеры. К тому же вполне возможно, что относительно сдержанный рост капитализации «Газпрома», «Аэрофлота» и «Ростелекома» обусловлен нефундаментальными, спекулятивными факторами, о которых упоминалось ранее. По крайней мере, восстановление фондового рынка только началось, и, наверное, рано делать какие-то далеко идущие выводы. Впоследствии, по истечении достаточно продолжительного времени, можно будет оценить корреляцию скорости восстановления стоимости акций и баланса интересов.

Итак, мы установили, что баланс интересов является значимым фактором изменения рыночной стоимости. Чем выше баланс интересов, тем выше рыночная стоимость бизнеса. 
Это подтверждает проведенное нами исследование корреляции баланса интересов и рыночной цены некоторых наиболее ликвидных акций. Целенаправленно регулируя баланс интересов, наемный менеджмент может управлять рыночной стоимостью бизнеса, независимо от обращаемости акций на рынке ценных бумаг.

\section{Список литературы}

1. Тонких А.С., Ионов А.В. Управление стоимостью бизнеса на основе баланса интересов // Вестник Финансовой академии. 2009. №3 (51). С. 50-57.

2. Сыроежин И.М. Совершенствование системы показателей эффективности и качества. М.: Экономика, 1980.

3. Тонких А.С. Моделирование результативного управления корпоративными финансами. Монография. Екатеринбург - Ижевск: ИЭ УрО РАН. 2006.

4. Кашин С. Как расти здоровым. // Секрет фирмы. 2004. № 29.

5. Сайт «Новые технологии финансового анализа и корпоративного управления». Программа расчета баланса интересов. http://www.freean.ru/I_O Forms/calculations.php.

6. Методика расчета индекса PTC. http://www.rts.ru/index.cfm?id=704. 